\title{
Risk profiling and control of spontaneous combustion for coal mine closure
}

\author{
B Williams Flinders Power, Australia \\ K Donaldson Flinders Power, Australia \\ B Beamish B3 Mining Services, Australia
}

\begin{abstract}
The Leigh Creek Coal Mine, located approximately $550 \mathrm{~km}$ north of Adelaide in South Australia, operated between 1944 and 2015.

The coal, being a low rank sub-bituminous coal, is prone to self-heating and localised spontaneous combustion. Throughout the many decades of mining operation a significant body of knowledge was generated regarding the causal factors and more effective treatment strategies for spontaneous combustion. These strategies were effectively suited to an operational mine site, but not specifically designed, nor tested, for closure.
\end{abstract}

A swift decision to close in June 2015, followed by a short mining operations shutdown period, presented significant operational, technical and regulatory challenges. The subsequent joint risk mapping process employed by Flinders Power and South Australian Mining Regulators was a unique example of obtaining real-time objective evidence through leading-edge science in order to inform the risk profile, determine the appropriate risk management strategies for closure and develop an appropriate mine closure plan.

In developing the risk assessment for closure, the following three key assumptions needed to be tested.

1. Both the coal and the carbonaceous mudstone overburden sequences have the ability to self-heat to the point of thermal runaway. The extent of self-heating varies with geologic unit.

2. Over time the ability of coal and mudstone to self-heat to the point of thermal runaway reduces.

3. By reducing the batter angle of the dump face and covering with a layer of fine inert material the hazard likelihood and therefore the risk of spontaneous combustion is reduced.

These assumptions were founded on operational experience and expert advice, however applicability to a rehabilitation phase had not been validated for the site.

To address these uncertainties extensive laboratory test work and a unique field trial installation on an area of active combustion was conducted. The testing of these assumptions formed the basis of the rehabilitation specification, area-specific rehabilitation designs and subsequent completion criteria. The use of a risk and evidentiary-based approach to categorise spontaneous combustion hazard likelihood for developing an appropriate rehabilitation design across the vast $70 \mathrm{~km}^{2}$ open cut coal mine forms the basis for this paper.

Keywords: open cut coal mine rehabilitation, spontaneous combustion, closure risk management

\section{Introduction}

In June 2015, the Alinta Energy Board announced the closure of the Flinders Power South Australian business, including the Leigh Creek Coal Mine, the Northern and Playford Power Stations located at Port Augusta and the $250 \mathrm{~km}$ railway line. The announcement was preceded by a brief period of internal planning. Coal mining operations ceased in November 2015. 
The Leigh Creek Coal Mine is a low rank sub-bituminous coalfield, unique in many ways. Located approximately $550 \mathrm{~km}$ north of Adelaide (Figure 1) the site has over 100 years of history and was formerly operated by the South Australian Government. Privatisation in 2000 saw the mine continue operation under Perpetual Leases from the South Australian Government.

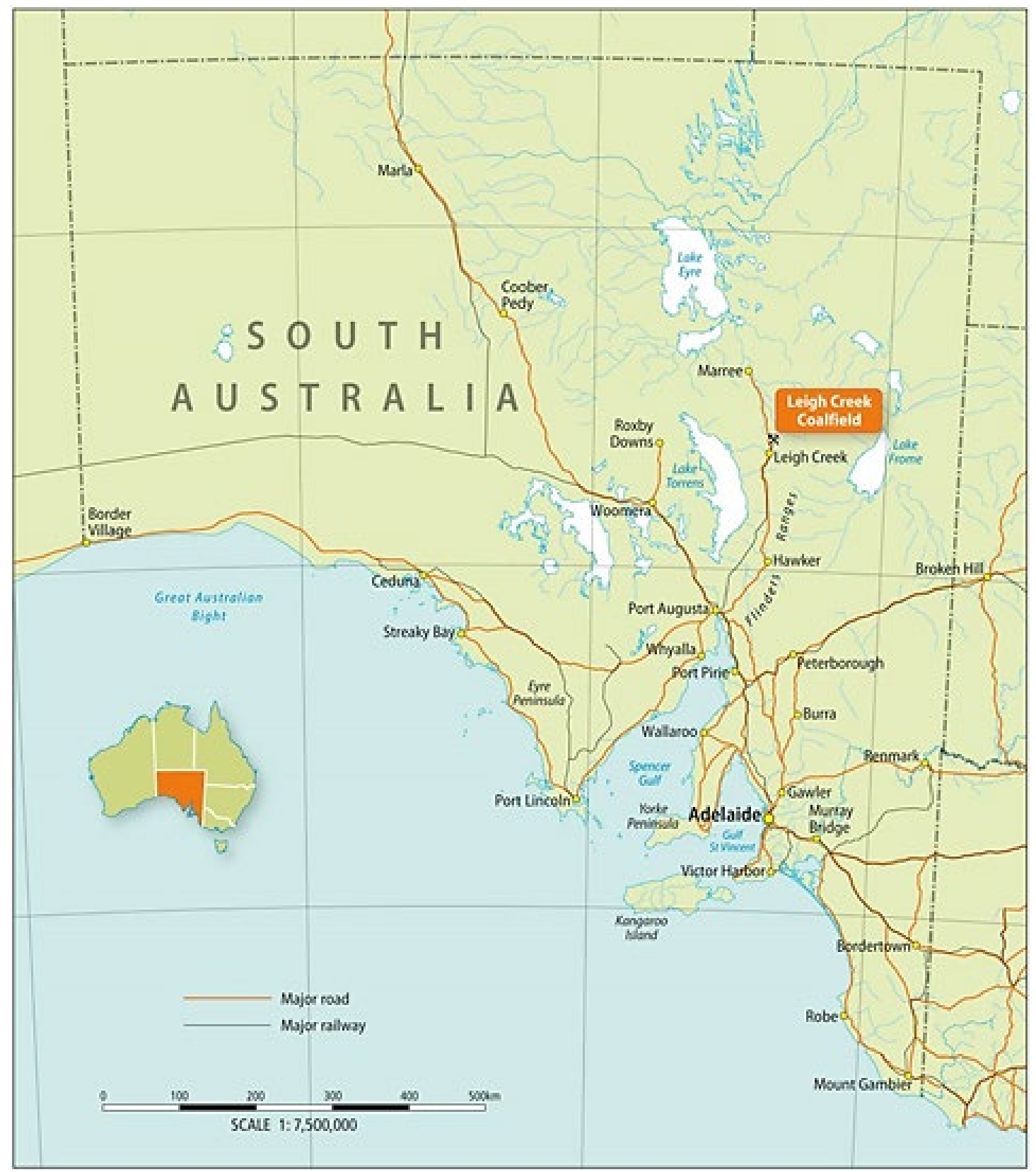

Figure $1 \quad$ Location map

The coal is hosted within a Triassic sedimentary sequence, underlain by Pre-Cambrian basement and occurring within four distinct lobes (Parkin 1953). The coal within Lobe B was deposited in three series termed Upper, Main and Lower Series (Figure 2). 

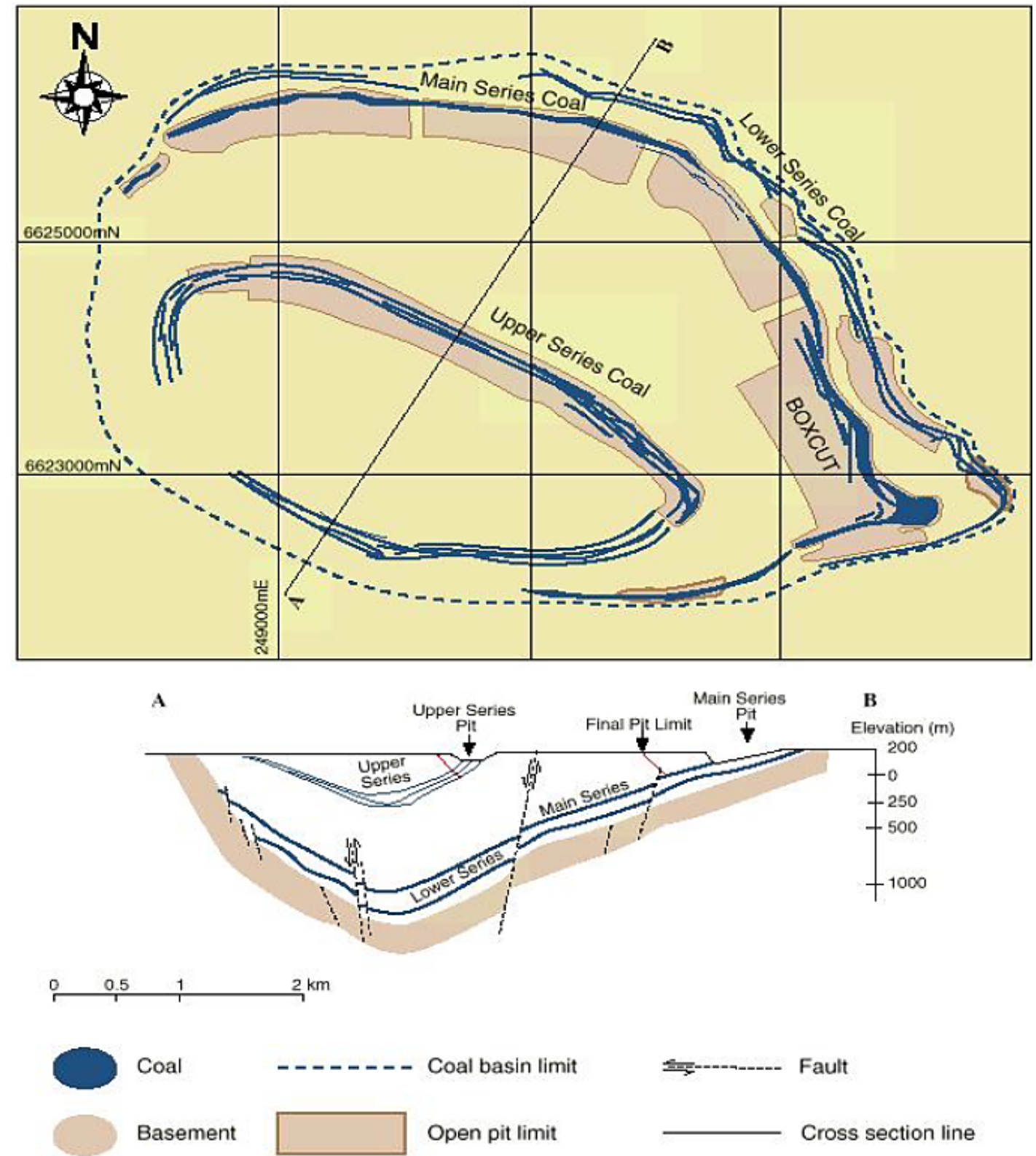

Figure 2 Leigh Creek Coalfield - Lobe B (after Dames \& Moore Pty Ltd 1984)

Salmon (2017, p. 22) states:

Each mine is unique... hence uncertainty in planning and implementing coal mine closure activities is inevitable.

While this was true in the instance of Leigh Creek mine closure, the ambiguity of uncertainty can be countered by an agreed risk management process where closure objectives and the behaviours of all parties are aligned (Williams \& Querzoli 2018).

\section{$2 \quad$ Risk profiling}

Inputs to the closure risk mapping process included the consideration of closure objectives, compliance obligations, lease conditions and the Environmental Protection Authority licence (Figure 3). The risk assessment process followed a source-pathway-receptor approach workshopped by Flinders Power, the Department of Energy and Mining and a number of independent experts. Identified risks to successful closure were to be controlled via a series of existing controls (developed from decades of onsite knowledge and supported by existing standard operating procedures) and future controls that formed the basis of the mine 
closure rehabilitation works plan. Individual risks and their control strategies were mapped against unique closure criteria specific to unique Leigh Creek mine geographic domains that would form the basis for assessing completion.

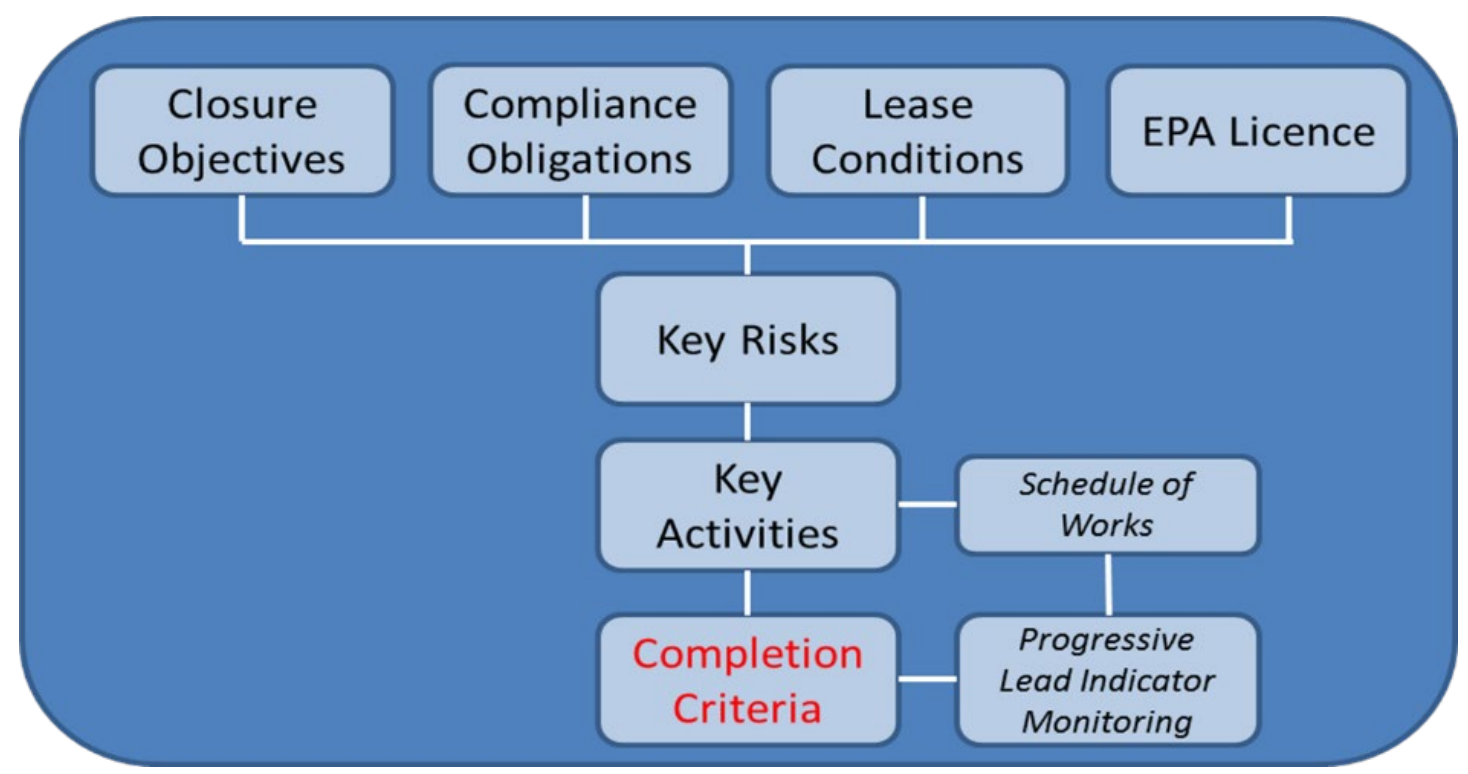

Figure 3 Risk profiling for Leigh Creek mine closure (Source: Flinders Power 2018)

\subsection{Assumptions and uncertainties}

In developing the risk assessment for closure, the following three critical assumptions were identified as needing validation. These assumptions were founded on operational experience and expert advice successfully employed as active management protocols during the operational phase of the mine lifecycle, however applicability to a rehabilitation phase was unvalidated at the site:

1. Both the coal and the carbonaceous mudstone overburden sequences have the ability to self-heat to the point of thermal runaway. The extent of self-heating varies with geology.

2. Over time the ability of coal and mudstone to self-heat to the point of thermal runaway reduces.

3. By reducing the batter angle of the dump face and covering with a layer of fine inert material the hazard likelihood and therefore risk of spontaneous combustion is reduced.

To address these uncertainties extensive laboratory test work and a unique field trial installation on an area of active combustion was conducted across a three-year period.

\subsubsection{Assumptions 1 and 2: ability to self-heat to thermal runaway; ability to self-heat reduces over time}

While all coal seams have some propensity to spontaneously combust, the magnitude of the problem depends on a complex interrelationship of a range of factors (Phillips et al. 2011). In understanding the propensity for Leigh Creek coal and overburden to self-heat to the point of thermal runaway, it was vital to first understand the intrinsic and extrinsic characteristics of the material that may promote self-heating. Once understood, this knowledge could then be integrated with operational experience, industry experience and leading practice for the rehabilitation of open cut coal mines (Figure 4). 


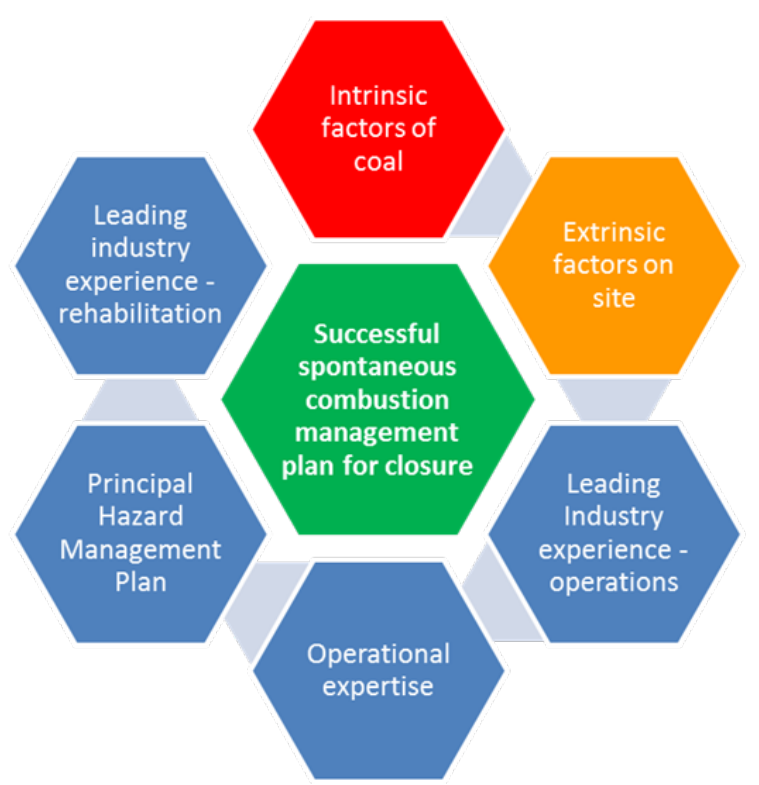

Figure 4 Factors influencing spontaneous combustion control for closure (source: Flinders Power 2018)

Factors affecting spontaneous combustion can be split into intrinsic and extrinsic factors (Phillips et al. 2011). The same approach has been used to determine the propensity for spontaneous combustion at Leigh Creek coalfields.

Major coal intrinsic factors were defined by Beamish (2014):

- Rank.

- Particle size.

- Specific heat.

- Gas.

- Porosity.

- Mineral matter.

- Moisture.

- History.

- Petrology.

To assess the propensity and likelihood for spontaneous combustion, the following tests were conducted on samples of Leigh Creek Lower Series coal (boreholes 7030 and 7032) in 2013. At the time, the Lower Series coal seam was being investigated for future development. Drillcore was taken, sealed and analysed by B3 Mining Services for:

- Intrinsic spontaneous combustion propensity - using the adiabatic oven $\mathrm{R}_{70}$ test procedure. Full details of the test methodology are given in Beamish et al. (2000). The coal sample is dried under nitrogen at $110^{\circ} \mathrm{C}$ before reintroduction of oxygen at $40^{\circ} \mathrm{C}$ and subsequent tracking of increase in thermal oxidation over time. The test measures the time taken for the dry, crushed coal to increase in temperature from $40^{\circ} \mathrm{C}$ to $70^{\circ} \mathrm{C}$ due to oxidation under adiabatic conditions. A relative scale developed by Beamish \& Beamish (2011) is used to rate the intrinsic spontaneous combustion propensity of the coal. The $\mathrm{R}_{70}$ test also produces a value for the relative ignition temperature (RIT) of the coal.

- Spontaneous combustion likelihood under site conditions using the adiabatic oven incubation test procedure. This test is designed to replicate the true coal self-heating behaviour from low ambient 
temperature. As such, the normal in-mine temperature is used as the starting point for the test. The nature of the test also assumes that in the real operational situation there is a critical coal pile thickness present that minimises any heat dissipation (represented by the adiabatic oven testing environment) and there is a sufficient supply of oxygen present to maintain the oxidation reaction. A larger sample mass and lower oxygen flow rate is used, compared to the $R_{70}$ test method, to produce conditions that more closely match reality. The coal sample either reaches thermal runaway, or begins to lose heat due to insufficient coal intrinsic reactivity to overcome heat loss from moisture evaporation and/or heat sink effects from non-reactive mineral matter. As the coal is tested with its as-received moisture content, for some coals this may produce a prolonged temperature shoulder on the way to thermal runaway. This feature of the coal self-heating is not identified by the older $\mathrm{R}_{70}$ test, which only measures the coal intrinsic reactivity on a dry basis.

The self-heating behaviour of the coal recorded by the incubation test is compared against the documented self-heating performance of a range of coals with known spontaneous combustion precedent. Due to the nature of the moisture evolution that occurs during the coal self-heating, the time taken for the coal temperature to reach $120^{\circ} \mathrm{C}$ is used as the key indicator of the coal to reach thermal runaway (tTR). This value is obtained in laboratory hours and is converted to site days using the comparison with coals of known behaviour.

Based on the $\mathrm{R}_{70}$ values, the samples have a High to Extremely High intrinsic spontaneous combustion propensity rating ('ISCP', Table 1) that is consistent with the low rank of the coal. There is also a general trend of decreasing $R_{70}$ value with increasing ash content, due to the heat sink effect of the mineral matter present in the coal. While there are many seams across the coalfield, the Lower Series coal seams investigated were considered to be 'worst-case'.

Table $1 \quad R_{70}$ and relative ignition temperature (RIT) values of Lower Series Coal samples

\begin{tabular}{|c|c|c|c|c|}
\hline Sample & Ash content $(\%, \mathrm{db})$ & $\mathrm{R}_{70}\left({ }^{\circ} \mathrm{C} / \mathrm{h}\right)$ & $\operatorname{RIT}\left({ }^{\circ} \mathrm{C}\right)$ & ISCP QId rating \\
\hline \multicolumn{5}{|l|}{7030} \\
\hline Sample 1 & 42.6 & 3.98 & 180 & High \\
\hline Sample 3 & 19.2 & 15.92 & 113 & Ultra high \\
\hline Sample 4 & 34.1 & 6.3 & 158 & Very high \\
\hline \multicolumn{5}{|l|}{7032} \\
\hline Sample 2 & 13.0 & 12.69 & 111 & Ultra high \\
\hline Sample 7 & 13.7 & 12.23 & 117 & Ultra high \\
\hline Sample 13 & 15.6 & 16.28 & 119 & Extremely high \\
\hline
\end{tabular}

Incubation testing of the samples provided a more accurate assessment of the spontaneous combustion hazard likelihood. The initial conditions for the selected samples are listed in Table 2, with the test outcomes shown in Figure 5.

Table 2 Incubation test initial conditions

\begin{tabular}{lccc}
\hline Sample & Initial temperature $\left({ }^{\circ} \mathrm{C}\right)$ & Moisture content (\%) & Ash content (\%) \\
\hline $\mathbf{7 0 3 0}$ & & & \\
Sample 3 & 40.2 & 28.8 & 5.8 \\
$\mathbf{7 0 3 2}$ & & & \\
Sample 13 & 40.3 & 28.8 & 11.7 \\
Sample 13 & 40.2 & 25.7 & 12.2 \\
\hline
\end{tabular}




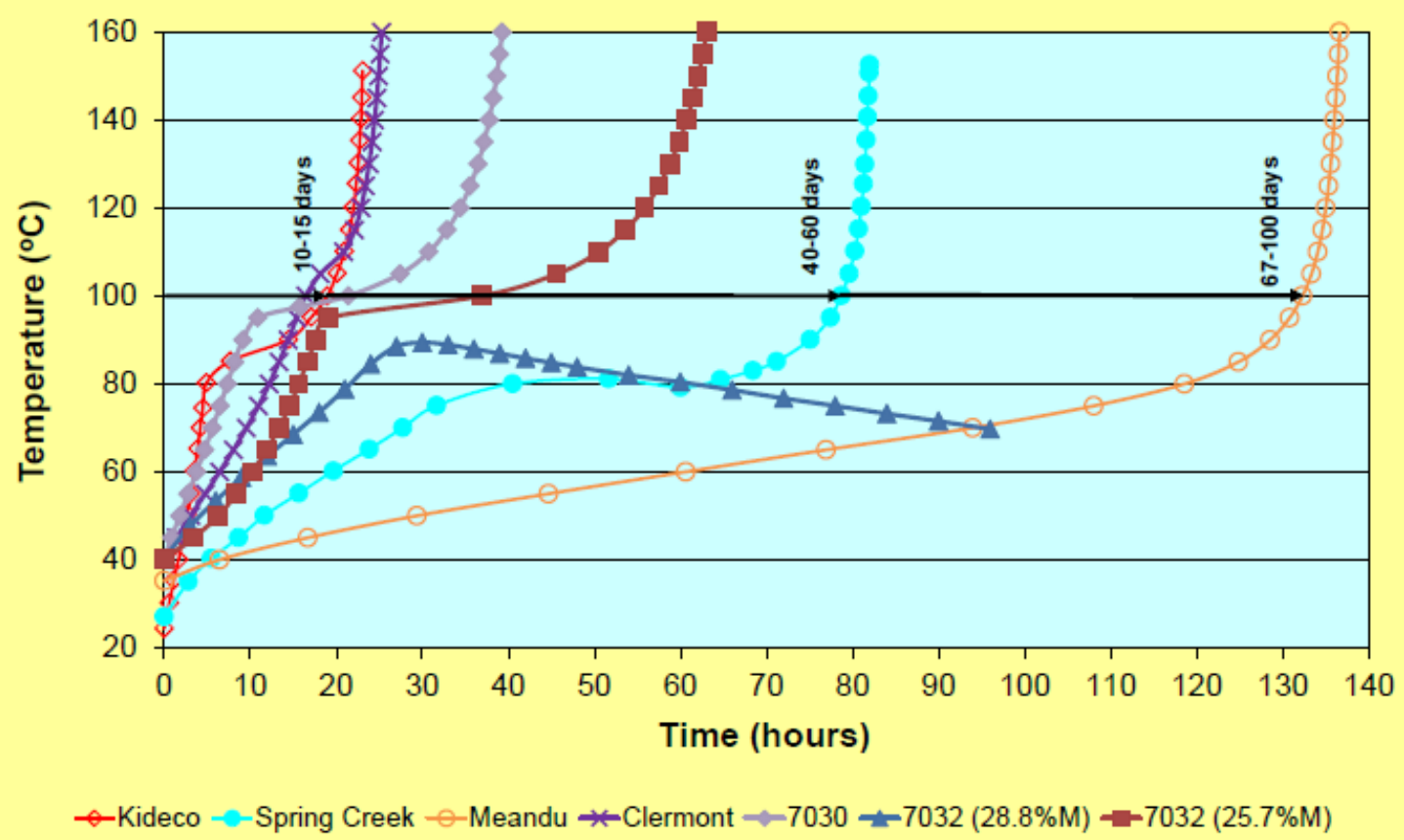

Figure 5 Incubation test results for samples from Leigh Creek boreholes compared with coals of known self-heating behaviour

The incubation test results showed that under replicated field conditions, sample 3 from borehole 7030 reached thermal runaway relatively quickly, with a short moderating moisture shoulder once the coal reached $95^{\circ} \mathrm{C}$ (Figure 6). Based on previous benchmarking work conducted by B3 Mining Services, this suggests that the sample of coal would take a minimum of 11-17 days to reach thermal runaway if a loose pile of this coal is formed at a critical thickness with sufficient continuous air supply and minimal heat dissipation. It should be noted that the ash content of the incubation test sample was much lower than the $R_{70}$ test sample shown in Table 1 and therefore the $R_{70}$ value would have been much higher. Consequently, the intrinsic reactivity of the sample was sufficient to overcome the heat loss from the $28.8 \%$ moisture present in the coal.

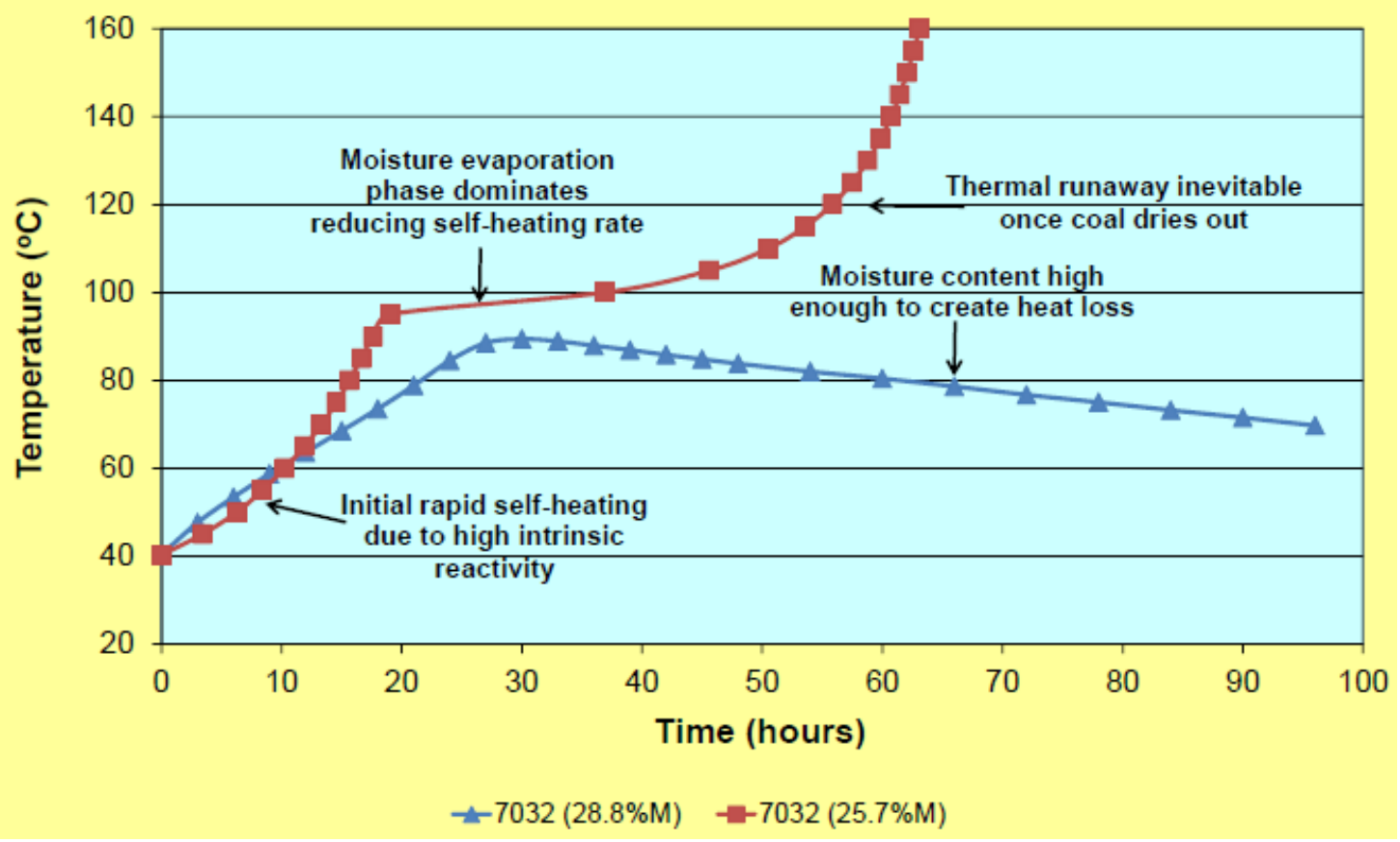

Figure 6 Incubation test results for samples 7032 - as-received moisture and reduced moisture 
Sample 13 from borehole 7032 had a moisture content of $28.8 \%$, but it also had a higher ash content and therefore lower intrinsic reactivity to sample 3 from borehole 7030 . It initially self-heated to $90^{\circ} \mathrm{C}$ before gradually losing heat from moisture evaporation. The sample was re-tested with $3.1 \%$ moisture removed, and this was sufficient to tip the balance in favour of heat gain and thermal runaway (Figure 5).

In 2016 B3 Mining Services were re-engaged by Flinders Power to conduct extensive laboratory analysis of the spontaneous combustion propensity of varying types and ages of material present across the mine. This built from the learnings of the 2013 investigation. Sixty-one samples were supplied from six different material types covering a range of geology, age and mining method. The principal objective was to define areas of the mine that were at a higher risk of spontaneous combustion during the closure phase, so that rehabilitation treatments could be focused in those areas, mitigating the risk of materials self-heating to the point of thermal runaway, beyond which control of the heating becomes more difficult and resource intensive. Understanding the oxidation state of the samples was also considered an important objective to assessing whether a 'safe state' had been reached in aged materials. An initial coarse spontaneous combustion propensity rating of the samples was assessed from standard analytical parameters (total organic carbon, total sulphur, ash content and calorific value) obtained for the samples. $R_{70}$ and incubation testing was conducted on a range of selected samples.

Figure 7 shows the outcomes of $R_{70}$ testing on a variety of selected coal and overburden samples. The established $R_{70}$ curve from the 2013 work was compared against a previously published $R_{70}$ curve for Callide sub-bituminous coal, indicating a similar trend. Of note is the effect of ageing on the coal samples of relatively low ash content, indicated by samples SCP020 and SCP051 (coals mined less than two years ago) and SCP036 (coal mined four to five years ago). Within two years of open air exposure the typical $R_{70}$ values drop from circa $12^{\circ} \mathrm{C} / \mathrm{h}, \mathrm{db}$ to around $1-1.5^{\circ} \mathrm{C} / \mathrm{h}, \mathrm{db}$. Beamish et al. (2019) recorded similar relative decreases in $R_{70}$ values for ageing lignite samples.

All overburden samples recorded very low $R_{70}$ results, in the range $0-0.2^{\circ} \mathrm{C} / \mathrm{h}, \mathrm{db}$. Of particular note are the samples 'M2 stored' and 'BH7032 stored', being the original core samples that had been stored in a freezer in their original sealed wrapping for the previous two years since the initial investigations and therefore not subject to oxidation. These recorded a significant decrease in propensity rating as indicated by the $R_{70}$ values despite the fact they had been protected from air ingress. Beamish et al. (2000) recorded similar storage ageing effects for a New Zealand sub-bituminous coal.

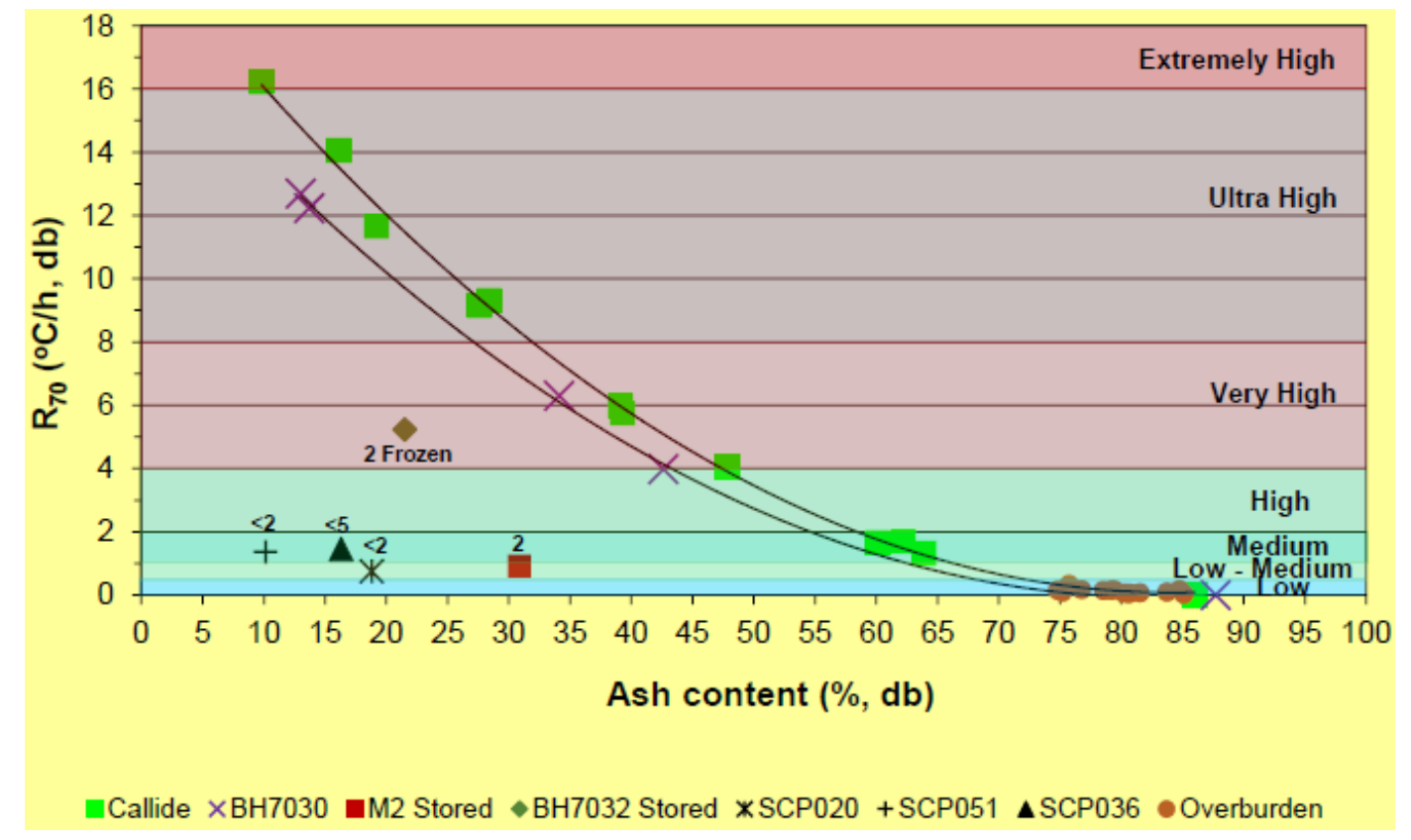

Figure 7 Self-heating relationship with ash content for fresh and aged mine materials 
The key outcomes of the investigation were:

- The carbonaceous overburden rocks from Leigh Creek mine have a retained fuel load that is related to the total organic carbon content of the samples. The fuel load is confirmed by the retained calorific value of the samples which ranged up to $4-6 \mathrm{MJ} / \mathrm{kg}$, $\mathrm{db}$ for some samples.

- The intrinsic reactivity of all the carbonaceous mudstone overburden samples is extremely low. For these rocks to develop to a spontaneous combustion event requires a heat source to elevate the rock temperature to a sufficiently high temperature for the organic carbon to sustain self-heating. This was confirmed by the $\mathrm{R}_{70}$ testing results that showed the samples have high RITs and very low self-heating rates.

- The presence of moisture in the carbonaceous mudstone samples moderates any self-heating and effectively eliminates any possibility of sustained self-heating at ambient mine temperatures. This was confirmed by the incubation testing results that showed the samples losing heat due to the presence of moisture.

- The past inference that the carbonaceous mudstone overburden has been responsible for the selfheating issues experienced at the mine is a misconception as the rock cannot initiate a spontaneous combustion event. The process that has taken place is that fugitive coal from the mining process has been mixed with the carbonaceous rocks and it is this coal that has initiated a hot spot, which has then elevated the temperature of the carbonaceous rocks to a point where they take over and the fuel load of the carbonaceous rocks is sufficient to continue self-heating to ignition. This is a classic case of the confusion that often exists between correlation and causation.

- The likelihood of developing a spontaneous combustion event decreases significantly with time as the carbonaceous material progressively oxidises and from the testing results obtained would appear to be negligible after five years.

- In addition, the fugitive coal remaining in the overburden spoil piles is subject to dilution.

In undertaking this work, Assumptions 1 and 2 were clarified. The test outcomes were used in the mine closure plan to determine high, medium and low risk areas of spontaneous combustion by combining the following criteria (actual classifications are tabled in the Approved Mine Closure Plan, Flinders Power 2018, p. 305):

- 'Geology' - a description of the mine geology, which defined 19 material sub-categories.

- 'Tested Intrinsic Spontaneous Combustion Propensity Qld Rating' - after Beamish \& Beamish (2011). This industry classification uses the tested $R_{70}$ value. The Queensland classification system is used as the weather conditions at Leigh Creek are considered more analogous in terms of ambient heating to conditions in Queensland.

- 'Possible Fugitive Coal' - a yes/no classification system to note where fugitive coals may be present.

- 'Time Since Mined' - since spontaneous combustion likelihood decreases over time, with progressive oxidation of available sites within the pore structure of the material, the time since the material was first exposed is a critical factor in determining the risk profile.

- 'History of Spontaneous Combustion' - through operational experience, the various geological classifications have been assessed using a yes/no classification system. The operational experience is supported by the evidence of the thermal imaging monitoring data.

- 'Previously Rehabilitated' - certain areas of the mine, particularly the historic surface waste dumps, have already received rehabilitation treatment.

This enabled mapping of spatial variability of spontaneous combustion risk (Figure 8). 


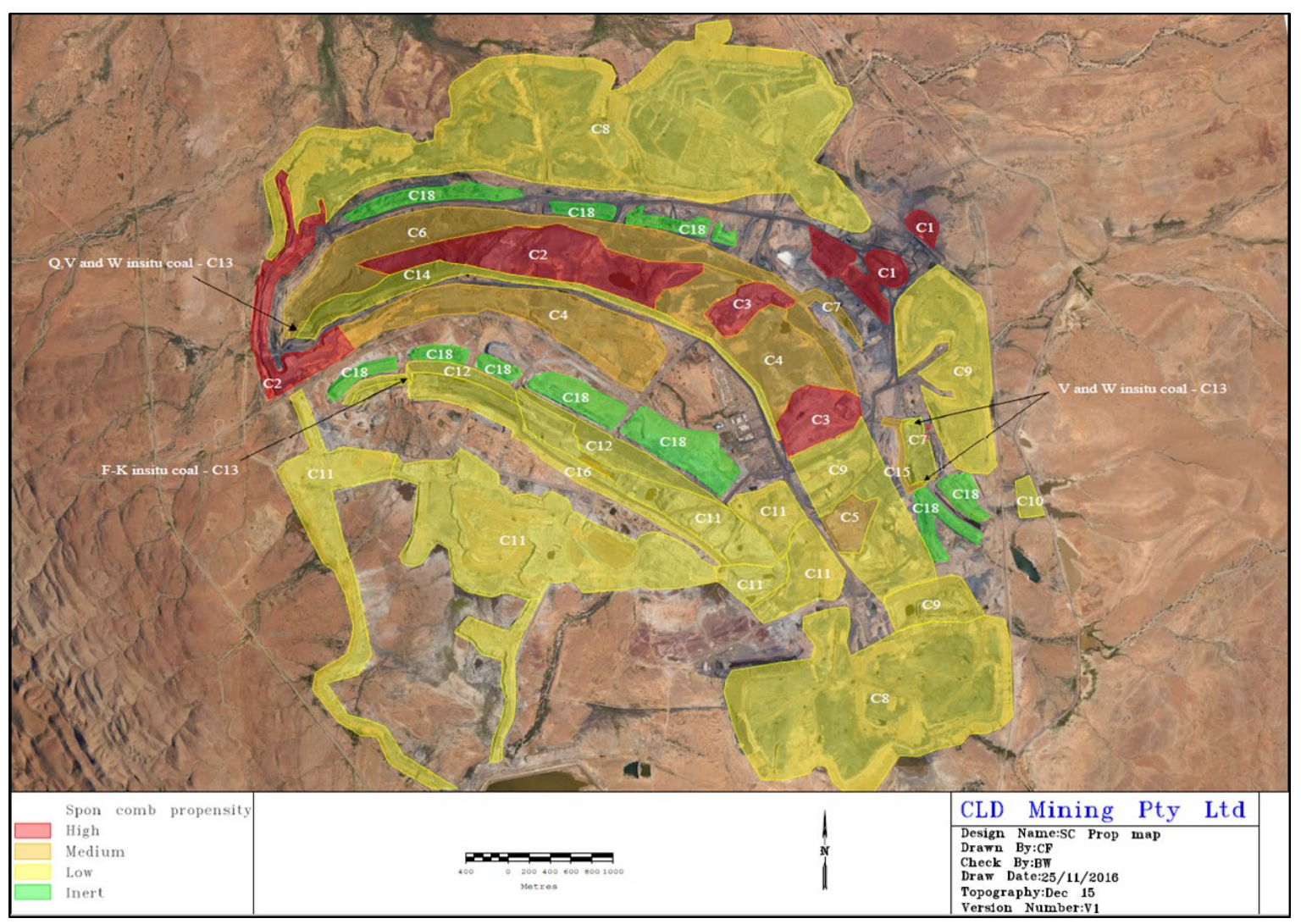

Figure 8 Spontaneous combustion risk map (red shading = high propensity; orange shading = medium propensity; yellow shading = low propensity; green shading $=$ inert/nil propensity)

This desktop study was supported by comprehensive spatial thermal imaging across the mine. A total of 114 locations were selected for hand-held imaging of surface dumps, low, end and highwalls, pit floor, in-pit dumps and stockpiles. Data inputs shown in Figure 9 were used to determine the spatial risk classification in Figure 10, taken at the commencement of the rehabilitation works period. Monitoring was repeated quarterly and expanded on previous operational databases. The risk classification is the overall score of the summation of individual values.

\begin{tabular}{|c|c|c|c|c|c|}
\hline Risk Value & $\begin{array}{c}\text { Temperature } \\
\text { (IR monitoring) }\end{array}$ & Visible Smoke & $\begin{array}{c}\text { Presence of } \\
\text { loose material }\end{array}$ & $\begin{array}{c}\text { Height of steep } \\
\text { slope (angle of } \\
\text { repose) }\end{array}$ & $\begin{array}{c}\text { Presence of } \\
\text { water }\end{array}$ \\
\hline 1 & $\begin{array}{c}\text { Ambient } \\
\text { Temperature }\end{array}$ & $\begin{array}{c}\text { No history of } \\
\text { smoke sightings }\end{array}$ & $\begin{array}{c}\text { Material is } \\
\text { compacted }\end{array}$ & $<3 \mathrm{~m}$ & No water \\
\hline 2 & $\mathrm{~T}<50^{\circ} \mathrm{C}$ & $\begin{array}{c}\text { Rare } \\
\text { (few times per } \\
\text { year) }\end{array}$ & Mnimal $(<5 \%)$ & $>3 \mathrm{~m} \&<20 \mathrm{~m}$ & $\begin{array}{c}\text { Small patches of } \\
\text { wetness }\end{array}$ \\
\hline 3 & $50^{\circ} \mathrm{C}<\mathrm{T}<75^{\circ} \mathrm{C}$ & $\begin{array}{c}\text { Often } \\
\text { (at least once } \\
\text { per month) }\end{array}$ & $\begin{array}{c}\text { Some }(>5 \% \& \\
<50 \%)\end{array}$ & $>20 \mathrm{~m} \&<40 \mathrm{~m}$ & Wet \\
\hline 4 & $\mathrm{~T}>75^{\circ} \mathrm{C}$ & $\begin{array}{c}\text { Always Smoking } \\
\text { (at least once } \\
\text { per week) }\end{array}$ & Majority $(>50 \%)$ & $>40 \mathrm{~m}$ & $\begin{array}{c}\text { Ponding, or in pit } \\
\text { lake }\end{array}$ \\
\hline
\end{tabular}

\begin{tabular}{|c|c|c|c|}
\hline Low & Moderate & High & High \\
\hline 11 & 15 & 18 & 20 \\
\hline Low & Moderate & Moderate & High \\
8 & 12 & 16 & 19 \\
\hline Very Low & Low & Moderate & Moderate \\
6 & 9 & 13 & 17 \\
\hline Very Low & Very Low & Low & Moderate \\
5 & 7 & 10 & 14 \\
\hline
\end{tabular}

Figure 9 Spontaneous combustion hotspot risk analysis matrix 


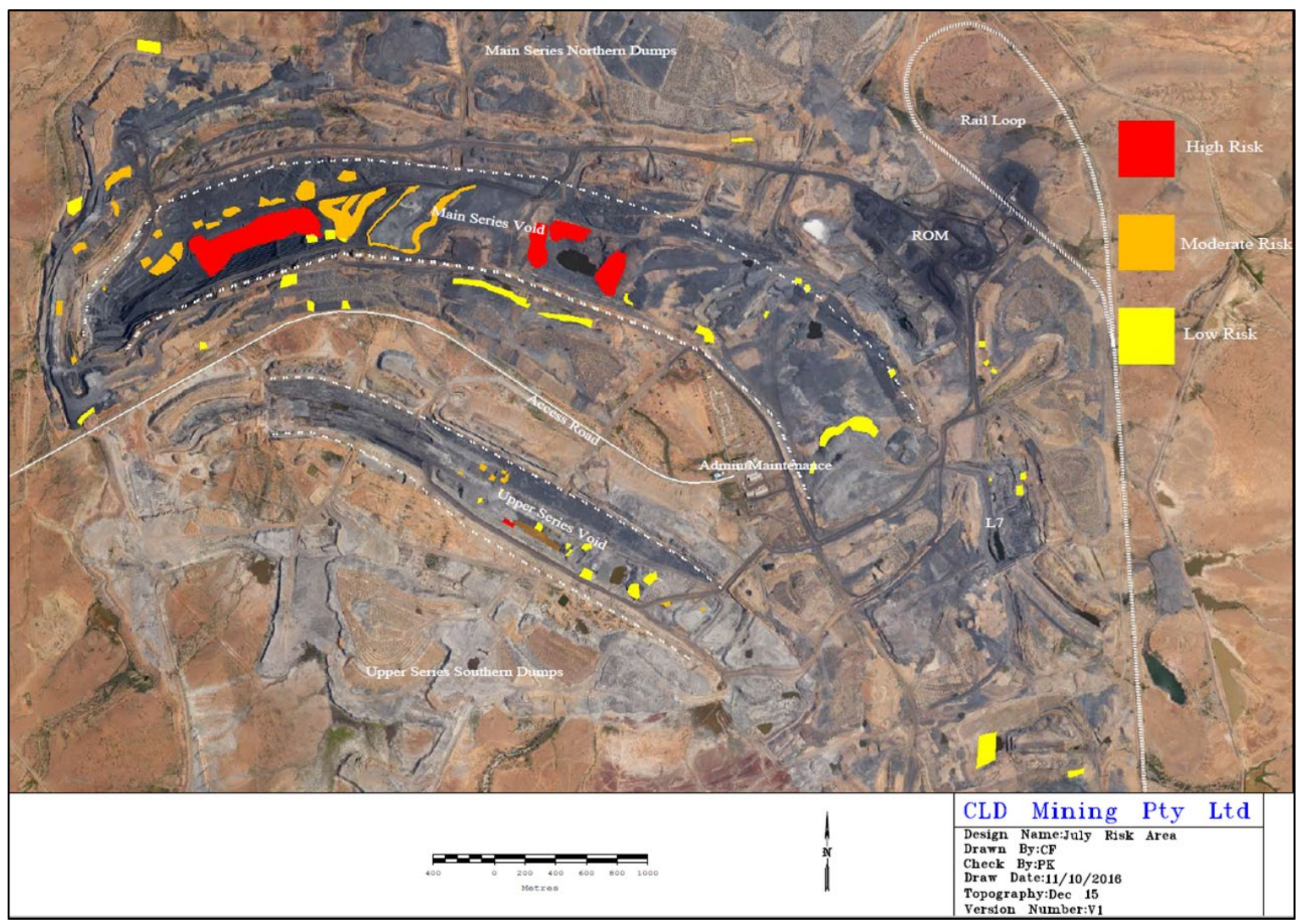

Figure 10 Thermal imaging risk map - July 2016 (red shading = high risk; orange shading = moderate risk; yellow shading $=$ low risk)

The thermal surveys (Figure 10) demonstrated a clear correlation with the risk map (Figure 7). The result was a comprehensive mine-wide assessment enabling rehabilitation efforts to be tailored towards the high-risk locations of the mine.

\subsubsection{Assumption 3: Reducing the dump face batter angle and covering with a layer of fine inert material reduces the risk of spontaneous combustion}

Commencing in 1989 the Leigh Creek coalfields initiated extensive technical studies to inform their management practices for spontaneous combustion, and thus have more than 25 years of operations experience founded on scientific understanding of the specific characteristics of Leigh Creek materials and environment. In Australia, the open cut coal industry itself, through ACARP (Australian Coal Association Research Program), has supported research in the area for at least 15 years (Day 2008). Consequently, there is a large body of scientific and technical literature on the subject. However, the literature is often laboratorybased, rather than the examination of field-based trials.

Extrinsic factors, specific to the operational methods and environment, must be considered in conjunction with the intrinsic properties of the coal, to gain a complete understanding of the risk profile. Site and stockpile characteristics are the main extrinsic factors contributing to the likelihood of a spontaneous combustion event developing. Beamish (2014) noted the following factors that are all important at Leigh Creek coalfields:

- Site induced heating by interaction between mining and the geological setting.

- Geographical location. In hot climates the coal oxidation will have a head start on the self-heating curve.

- Changing from dry season to wet season can initiate heatings due to additional heat generated from the coal adsorbing moisture from the surrounding environment, creating a 'heat of wetting effect'. 
- Prevailing wind directions and strength can also increase the risk of spontaneous combustion due to additional chimney effects created and loose coal on benches.

- Stockpile height.

- Stockpile porosity.

- Stockpile slope angle.

It is widely recognised that the phenomenon of spontaneous combustion requires access to a supply of oxygen for the reaction to continue (Arisoy et al. 2006).

The thickness of seal material required to control spontaneous combustion will vary, depending on the seal material properties and the reactivity of the coal. Cliff et al. (2014) notes 'clay rich materials with high water retention capacity can form effective barriers when $1-2 m$ thick'.

Eroglu \& Moolman (2003) relate the reactivity of a coal to be covered to the thickness of the coverage required:

A very reactive coal needs just a thin layer of sealing material in order to consume the oxygen at the coal surface because of the fast reaction. The surface of the high reactive coal consumes a lot more oxygen than the medium or low reactive coal. The thickness of the layer, and thus the oxygen ingress to the coal, and the reactivity of the coal reach equilibrium. This equilibrium ensures that the oxygen that enters is consumed by the surface of the coal and hence no more oxygen is available to ingress further in to the dump. This sealing technique prevents spontaneous combustion.

Following extensive literature review and technical advice, the following strategies were adopted as the base approach for rehabilitation at the Leigh Creek mine:

In-pit:

- Extinguish any existing fires/hotspots.

- Dig out all loose material on berms and batters.

- Monitor temperature. If there is evidence of heating, then initiate reprofiling and covering.

- Control of water - ensure no flows over crests.

Waste dumps:

- Extinguish any existing fires/hotspots.

- Single batter slope where slope vertical height is less than $40 \mathrm{~m}$.

- Reduce overall slope angles to 1:4.5 where spontaneous combustion susceptible material is present as evidenced by monitoring program. In areas where 1:4.5 cannot be achieved, re-profile to 1:3.

- Cover with fines dominated, clay rich, inert cover material.

- Minimum $1 \mathrm{~m}$ (post-compaction/completion) inert material cover thickness. It should be noted that:

- $2 \mathrm{~m}$ inert material cover (loose) was applied on all re-profiled slopes of the major pit voids. This equated to a minimum of $1.4 \mathrm{~m}$ post-compaction/completion.

- $1.7 \mathrm{~m}$ (loose) inert cover was applied to all other designs where cover is proposed. This equated to a minimum of $1.2 \mathrm{~m}$ post-compaction/completion.

- Grade on the contour to reduce gullies created by vertical dozing. This could only be safely achieved on 1:4.5 rehabilitated slopes.

- Control water with surface water bunding at crest and silt traps at the toe of critical locations. 
- Divide ramps, haul roads, former stockpiles into catchment cells by bunding to minimise water movement.

The rehabilitation works program delivered 14 million loose cubic metre $(\mathrm{lcm})$ of earthworks utilising 65,000 machine hours over a three-year period, incorporating:

- Overburden dump reprofiling.

- Inert cover placement - 4 million Icm of material sourced, sampled, excavated, trucked and dozed into position.

- Surface water and safety bund controls $-153 \mathrm{~km}$ of $3 \mathrm{~m}$ high $\times 9 \mathrm{~m}$ wide bunds constructed.

- Demolition works - charge felling and scrap processing.

- Asset sale process - two public auctions and over 50 major items of the mining fleet.

- The construction and management of major industrial and asbestos waste facilities.

To verify the completion of as-built works to plan, data packs have been prepared against specific completion criteria and independently verified (Jones \& Franklin 2019). Over 117 unmanned aerial vehicles (UAV) flights have been conducted by CLD Mining Pty Ltd covering a distance of 2,925 km.

In order to determine the effectiveness of this strategy, a monitoring trial of the selected rehabilitation strategy was established by sonic drill rig in a location that was actively combusting prior to rehabilitation treatment. Measurements of temperature and oxygen concentration at varying depths within the rehabilitated dump show that oxygen supply is limited, and there has been a net heat loss from the trial area. Further details of the field trial are outlined in Garvie et al. (2019). To date, assumption 3 has been validated.

\section{Conclusion}

Closure planning and implementation at the Leigh Creek mine sets a new benchmark, with lessons in innovation and leadership being progressively shared across the industry. The joint risk mapping process by Flinders Power and South Australian Mining Regulators is a unique example of collaborative mine closure execution. The extensive scientific research program brought together collective Australian expertise into an appropriate closure plan. The closure plan has been implemented and verified. At the time of preparing this paper, no rehabilitated areas of the mine were subject to any instances of spontaneous combustion. Monitoring across a post-completion monitoring and minor works period will continue to determine the effectiveness of the control strategy over time.

This real-world example demonstrates the importance of change in mindset from short-term operational controls to long-term closure controls. It demonstrates that while risk mapping is an important subjective tool, the true benefit is derived when objective evidence is sourced to define assumptions and uncertainties.

\section{Acknowledgement}

Flinders Power would like to acknowledge the dozens of independent consultants, regulators, management and staff who have been integral to developing and implementing the Leigh Creek mine closure plan. The successful program could not have been completed without your support.

\section{References}

Arisoy, A, Beamish, B \& Cetegen, E 2006, 'Modelling spontaneous combustion of coal', Turkish Journal of Engineering and Environmental Science, vol. 30(2006), pp. 193-201.

Beamish, B 2014, Review of spontaneous combustion management at Leigh Creek Coal Mine, B3 Mining Services Technical Report 2014/TR001.

Beamish, B \& Beamish, R 2011, 'Testing and sampling requirements for input to spontaneous combustion risk assessment', in B Beamish \& D Chalmers (eds), Proceedings of the Australian Mine Ventilation Conference, The Australasian Institute of Mining and Metallurgy, Melbourne, pp. 15-21. 
Beamish, B, Barakat, MA \& St George, JD 2000, 'Adiabatic testing procedures for determining the self-heating propensity of coal and sample ageing effects', Thermochimica Acta, vol. 362, no. 1-2, pp. 79-87.

Beamish, B, Theiler, J \& Garvie, A 2019, 'Ageing effect on the self-heating incubation behaviour of lignite', in N Aziz \& B Kininmonth (eds), Proceedings of the Coal Operators' Conference, The University of Wollongong, Wollongong, pp. 260-264.

Cliff, D, Brady, D \& Wilkinson, M 2014, 'Developments in the management of spontaneous combustion in Australian underground coal mines', Proceedings of the 14th Coal Operators Conference, The Australasian Institute of Mining and Metallurgy, Melbourne, pp. 330-338.

Dames \& Moore Pty Ltd 1984, Leigh Creek Coalfield: Lobe B, Geotechnical and Hydrogeological Investigations, Phase 1, Groundwater and Dewatering, October 1984.

Day, S 2008, Spontaneous Combustion in Open Cut Coal Mines, Final Report for ACARP Project C17006, http://www.acarp.com.au

Eroglu, N \& Moolman, C 2003, Develop methods to prevent and control spontaneous combustion associated with mining and subsidence, Coaltech 2020 Project 3.4.1, http://www.coaltech.co.za

Flinders Power 2018, Approved Mine Closure Plan, http://www.energymining.sa.gov.au/minerals/mining/mines_and_quarries/ leigh_creek_coal_mine

Garvie, A, Donaldson, K, Williams, B \& Chapman, J 2019, 'A demonstration of the cessation of spontaneous combustion in a coal overburden spoil pile', in AB Fourie \& M Tibbett (eds), Proceedings of the 13th International Conference on Mine Closure, Australian Centre for Geomechanics, Perth, pp. 897-910.

Jones, P \& Franklin, C 2019, 'Relinquishment criteria verification: quality assurance/quality control using unmanned aerial vehicles,' in $A B$ Fourie \& M Tibbett (eds), Proceedings of the 13th International Conference on Mine Closure, Australian Centre for Geomechanics, Perth, pp. 1461-1476.

Parkin, L 1953, The Leigh Creek Coalfield, Bulletin No 31, South Australia Department of Mines, Geological Survey, KM Stevenson, Government Printer, Adelaide.

Phillips, H, Uludag, S \& Chabedi, K 2011, Prevention and Control of Spontaneous Combustion Best Practice Guidelines for Surface Coal Mines in South Africa, Coaltech Research Association.

Salmon, D 2017, Guidelines for Coal Mine Open Pit Final Void Closure and Relinquishment - Addressing Uncertainty in Coal Mine Environmental Planning, ACARP Project 25030, published 01/06/2017.

Williams, B \& Querzoli, A 2018, 'Risk management for minesite closure planning and execution - start now! Lessons from the closure of the Leigh Creek Coalfield, South Australia,' Proceedings of Life-of-Mine 2018, The Australasian Institute of Mining and Metallurgy, Melbourne, pp. 68-72. 